\title{
Editorial
}

\section{Nuevas miradas desde el bicentenario}

\author{
Natalia Sobrevilla Perea ${ }^{1}$ \\ Universidad de Kent. Canterbury, Reino Unido \\ N.Sobrevilla@kent.ac.uk \\ ORCID: 0000-0001-9592-7551
}

Citar como: Sobrevilla, N. (2021). Nuevas miradas desde el bicentenario. Desde el Sur, 13(3), e0026.

En esta edición de la revista Desde el Sur encontramos una serie de reflexiones sobre el Perú enmarcadas dentro de la conmemoración del bicentenario. Si bien solo una de ellas se enfoca en estudiar de manera directa el periodo de la independencia, y su análisis no se centra en cómo se logró la separación con España ni en las celebraciones realizadas en estos años de pandemia, sí queda claro que todos los trabajos de este número contribuyen a la comprensión del Perú en este contexto específico. El 2021 ha sido un año particular. Por un lado, el país y el mundo entero siguen inmersos en la realidad compleja y cambiante de la pandemia, mientras que, por el otro, el Perú ha vivido un intenso y desgastante proceso electoral que no ha logrado poner fin a la inestabilidad política que lo ha caracterizado los últimos cinco años.

\footnotetext{
1 Doctora por la Universidad de Londres (2005). Se licenció en la Pontificia Universidad Católica del Perú (PUCP) en 1996. Ha publicado Andrés de Santa Cruz, caudillo de los Andes (Fondo Editorial de la PUCP e Instituto de Estudios Peruanos, 2015), cuya versión en inglés apareció con Cambridge University Press en 2011, Los inicios de la república peruana. Viendo más allá de la «cueva de bandoleros» (Fondo Editorial de la PUCP, 2019) e Independencia. A 200 años de lucha por la libertad (Penguin Random House, 2021).

Asimismo, ha coeditado Compendio de los sucesos ocurridos en el Ejército del Perú y sus provincias (1813-1816), los diarios de campaña de Joaquín de la Pezuela (2011, reeditados por el Proyecto Bicentenario en 2020) y The rise of Constitutional Government in the Iberian Atlantic World. The impact of the Cádiz Constitution of 1812 (Alabama University Press, 2015).

Ha publicado más de una docena de artículos sobre historia política, social y militar de los Andes en el siglo XIX. Se ha desempeñado como profesora visitante en la Universidad de Yale (2005-2007), donde tuvo una beca predoctoral. Ha sido becaria de la John Carter Brown Library, la British Library, la British Academy, el Leverhulme Trust y la Fundación Alexander von Humboldt, gracias a la cual fue profesora visitante en la Universidad Libre de Berlín (20172018). Desde 2007 enseña catedra de Historia Latinoamericana en la Universidad de Kent.
} 
La encrucijada en la que nos encontramos al finalizar el año es particularmente compleja y nos hace difícil imaginar incluso cómo seguirán los próximos meses. Todo esto hace que las reflexiones sobre el pasado y el presente se vean teñidas de la indefinición que caracteriza el momento. A pesar de ello, las efemérides, en este caso la conmemoración de la proclamación de la independencia en Lima, nos llevan a pensar en el Perú y preguntarnos sobre lo que hemos logrado construir en un país tan complejo y dividido.

La pandemia desnudó la profundidad de las brechas sociales que caracterizan a nuestra nación, no porque necesariamente ignoráramos esa realidad, sino porque la crudeza de ver al país sumido en la crisis sanitaria hizo más difícil seguir volteándole la cara a nuestra realidad cotidiana: muchos en el Perú no tienen acceso a la salud, a una vivienda apropiada y a un trabajo digno. La implacable realidad nos hizo ver que si un bien como la salud se compra y se vende, pero hay escasez y limitaciones para prestar servicios, se llegará a un momento como el que sucedió en el país, en que hay un quiebre y ya ni el dinero puede protegernos.

Las elecciones fueron en gran medida el resultado de este contexto de precariedad. La desidia, el hartazgo y la sensación de que no hay salida posible llevaron a que muchos, en este año del bicentenario, pensaran que era necesario un cambio profundo. La pobre oferta electoral, a pesar del nutrido número de candidatos, hizo que la mayoría se enfocara en el candidato que les parecía más novedoso y más cercano, y fue así que Pedro Castillo conquistó suficientes votos para llegar a la segunda vuelta. Por el otro lado, Keiko Fujimori intentó por tercera vez llegar a la presidencia, representando a los grupos de poder económico, 
a los grandes ganadores del modelo que no quieren que nada cambie.

En este proceso de polarización extrema pensar en el Perú de manera amplia es muy complejo. Es posible interpretar la elección de Castillo como la forma en que un sector del Perú pide un cambio y una gran cuota de representación, aunque este pedido muy posiblemente quedará trunco, ya que queda claro que el presidente no parece tener ni las herramientas, ni la preparación, ni el equipo para llevar a cabo esta transformación. Y que aun si las tuviera, es muy posible que el statu quo se seguiría imponiendo.

En este escenario de contrastes con el que llegamos al final de 2021, presentamos seis artículos de corte muy diferente, que nos acercan a la sociedad peruana desde múltiples perspectivas. Dos de ellos tienen un enfoque histórico, uno presenta una mirada antropológica y culturalista, otro reflexiona sobre la construcción de la identidad sobre la base de la arqueología, y dos contextualizan las realidades de la migración venezolana al Perú en la coyuntura del bicentenario.

El artículo sobre el proceso de independencia estudia el encuentro entre Simón Bolívar y San Martín en el puerto de Guayaquil en julio de 1822. Este es sin duda uno de los episodios de las guerras de independencia sobre los que más se ha especulado, porque los libertadores decidieron que, al no ser una reunión oficial entre los representantes de dos naciones, no debía existir un registro oficial del encuentro. Esto ha llevado a interminables discusiones que buscan establecer con carácter definitivo qué se dijeron Bolívar y San Martín, cuál fue su intención al encontrarse y qué consecuencias tuvieron sus acciones. En el artículo se establece claramente lo que sabemos respecto al encuentro y se le diferencia de lo que ignoramos y sobre lo que 
tendremos siempre que especular, ya que las narraciones sobre los hechos son contradictorias y varían dependiendo de la persona que dejó el registro y su versión de lo que conversó con los protagonistas.

El siguiente artículo tiene también un corte histórico y se interesa por entender el mercado de esclavos negros en la Lima de la temprana república. Pese a que, en teoría, José de San Martín declaró la libertad de vientres en 1821, en realidad la compra y venta de personas seguía existiendo. El artículo se concentra en el periodo entre 1827 y 1832, y muestra la fluctuación en precio y valor de los esclavos, según la información aparecida en los anuncios del Mercurio Peruano. Lo novedoso de este enfoque es la atención a la estadística, el valor fluctuante y la lógica de mercado que gobernaban estas transacciones.

El objeto de estudio del siguiente artículo es el desarrollo de los discursos arqueológicos y cómo estos han servido y sirven en el proceso de la construcción de la identidad. Se trata de una forma de comprender la sociedad desde la importancia de usar el pasado milenario del Perú para argumentar que es una de las cunas de la civilización. Este artículo permite al lector comprender por qué y cómo se ha utilizado el conocimiento del pasado remoto para construir un discurso sobre el presente, al analizar las teorías de la difusión de la civilización, que forman parte del origen de la arqueología, y aplicarlas a su puesta en práctica en el Perú para afianzar la idea de identidad. En el contexto del bicentenario es particularmente relevante entender cómo sucede este proceso a través del tiempo.

El artículo sobre el testimonio en quechua, y la manera en que se organiza tomando las formas de un tejido, presenta un análisis muy rico sobre el funcionamiento de los códigos de un sector de la sociedad peruana sobre el que 
no se publica ni conoce lo suficiente. El trabajo muestra que existe un corpus de material de testimonio en quechua que nos ayuda a comprender un mundo extremadamente rico y complejo, como es el de los Andes peruanos, y que toda esa profundidad se refleja al abordar la salud, la enfermedad y la distribución social a través del uso de acertijos y mitos, así como el simbolismo de animales y plantas como la papa y el maíz. Esta aproximación nos acerca a un mejor conocimiento de nuestra sociedad y nos brinda herramientas para entablar una conversación con una multiplicidad de actores. Esto es extremadamente útil e importante en este momento bicentenario.

Una contribución muy interesante y que llena un vacío grande sobre la experiencia del bicentenario es la que se presenta en el artículo sobre cómo se sienten los migrantes venezolanos en este momento de conmemoración en el Perú, tomando en cuenta que tanto Simón Bolívar como Antonio José de Sucre fueron venezolanos. Se presenta una visión crítica que postula que la independencia no fue solamente un regalo de los libertadores, sino algo que debe estar vivo, lo que es una tarea para las generaciones presentes y futuras. En estas reflexiones sobre migración, ciudadanía y pertenencia se advierte la complejidad de las experiencias de estos grupos sociales, que no suelen ser dueños de su propia narrativa. El artículo está escrito en primera persona y visita momentos específicos de la historia y la actualidad, a fin de entender el Perú del bicentenario desde otra mirada.

El artículo final propone un estudio de la realidad de los migrantes venezolanos dedicados al comercio informal y cómo se enfrentan a la discriminación en la red social Twitter. Este trabajo se refiere de manera menos directa a la conmemoración del bicentenario, pero se inserta de modo preciso en una de las discusiones más complejas de 
la actualidad peruana: la de la discriminación y xenofobia que viven día a día los migrantes venezolanos. La especificidad del enfoque, que se concentra en una red social y en un colectivo particular, permiten que el tema se trate con profundidad y así colaborar con el conocimiento del fenómeno.

De esta forma, el presente número contribuye al estudio y la comprensión del Perú que llega al bicentenario en julio de 2021. No obstante la centralidad de esta fecha y la atención que se le presta en las conmemoraciones oficiales, se trata solamente de un hito en un proceso mucho más largo y complejo. Estos trabajos nos hacen reflexionar en un espacio temporal más amplio y preguntarnos, entre otros aspectos, sobre la reunión de los libertadores, el valor de los esclavos, el uso de la arqueología para crear identidad, la riqueza de los testimonios en quechua, la experiencia de los venezolanos en el Perú en tanto su visión del bicentenario y el modo en que encaran la discriminación en Twitter. Todo esto nos presenta una visión compleja y diversa sobre el Perú del bicentenario. 